www.jmscr.igmpublication.org

Index Copernicus Value: 79.54

ISSN (e)-2347-176x ISSN (p) 2455-0450

crossrefDOI: https://dx.doi.org/10.18535/jmscr/v7i1.197

\title{
Ultrasonography vs MRCP in Evaluation of Obstructive Jaundice
}

\section{Authors \\ Dr Sailendra Kumar Prusty ${ }^{1 *}$, Dr Savitri Bhagat ${ }^{2}$, Dr Braja Behari Panda ${ }^{3}$ \\ ${ }^{1}$ PG Resident, VIMSAR, Burla}

${ }^{2}$ Professor \& H.O.D., Department of Radiodiagnosis, Veer Surendra Sai Institute of Medical Sciences and Research (VIMSAR), Burla, Sambalpur, Odisha 768017

${ }^{3}$ Associate Professor, Department of Radiodiagnosis, Veer Surendra Sai Institute of Medical Sciences and

Research (VIMSAR), Burla

*Corresponding Author

Dr Sailendra Kumar Prusty

PG Resident, VIMSAR, Burla, Sambalpur, Odisha 768017, India

Email: prusty.sailendra@gmail.com, Mobile- 9861430101

Abstract
Obstructive jaundice results from obstruction to the flow of bile into the duodenum. The study was conducted
to evaluate imaging findings in USG and MRCP in 46 cases of suspected biliary obstruction during
November 2016 to October 2018. This cross sectional analytic study was conducted in Department of
Radiodiagnosis, VIMSAR, BURLA. All patients were subjected to USG \& MRCP. Results were compared and
found MRCP superior to USG in diagnosis of obstructive jaundice.
Keywords: Obstructive jaundice, USG, MRCP.

\section{Introduction}

Jaundice, also known as icterus, is yellow discoloration of the skin and sclera due to high bilirubin levels in the blood. It may be Hemolytic, Hepatocellular or Obstructive.

Obstructive jaundice results from obstruction to the flow of bile into the duodenum. Obstructive jaundice is not a disease in itself but a symptom of an underlying condition involving the liver, the gallbladder or the pancreas. It will usually require surgical intervention, and is also known as surgical jaundice. It is important to distinguish between the possible causes of obstructive jaundice.

So, it is mandatory to determine pre-operatively the existence, the nature and site of obstruction.
USG has been always considered the first choice technique in the study of biliary obstructive disease, due to its accessibility, speed, ease of performance and low cost ${ }^{1}$. Traditional Computed Tomography (CT) scan is usually considered more accurate than US for helping determine the specific cause and level of obstruction ${ }^{2}$. Ultrasound is used as an initial modality to confirm or exclude duct obstruction, which it does with at least $90 \%$ accuracy $^{3}$. The range of application of CT has been partially restricted by $\mathrm{MRCP}^{4}$. MRCP techniques have greatly evolved, providing high resolution images of the biliary tree with short exam duration, while remaining non invasive without contrast medium injection ${ }^{5}$. 


\section{Aims \& Objectives}

- To evaluate the cause and location of biliary obstruction

- To correlate MRCP with Ultrasonography in diagnosis of obstructive jaundice

- To find out types of lesion (benign/malignant) causing obstructive jaundice, age \& sex distribution.

\section{Material and Methods}

Patients with clinical and laboratory features suggestive of obstructive jaundice who were referred to Department of Radiodiagnosis, VIMSAR, Burla during the study period of 2 years (November 2016- October 2018) were included in the study.

\section{Exclusion criteria}

$>$ Patients having cardiac pacemakers and electromagnetic implants.

$>$ Patients with claustrophobia

$>$ Patients not giving the consent for study.

$>$ No obstructive pathology detected in USG

46 patients included in the study were subjected to abdominal ultrasound followed by MRCP (Ultrasound by Philips HD 7 machine and GE LOGIQ F8 Expert and MRCP by 1.5 Tesla GE signa machine). Various features of obstructive jaundice like presence and level of obstruction, cause of obstruction, extent of obstruction and other associated findings were studied on both. MRCP findings were compared with USG findings. The findings were tabulated and analyzed.

\section{Results}

Out of 46 patients evaluated, maximum numbers of cases were observed in 35-75 years of age group. Majority of benign cause were seen in 1150 years of age group while malignant causes were more common between 41-70 years of age group. Females $(52.17 \%)$ were slightly more than the males $(47.82 \%)$ in the study population. Jaundice, pain abdomen and vomiting were the frequent presenting complaints while fever, loss of appetite and distension of abdomen we less common. Most of patients presented with combination of symptoms ( $84 \%)$.

Majority of pathologies observed were benign (63.04\%). Most common benign disorder observed was choledocholithiasis (34.78) followed by benign strictures (10.86\%). Choledocholithiasis and cholelithiasis were more commonly observed in female patients. Least commonly observed benign pathologies were choledochal cyst $(8.69 \%)$ and pseudocyst $(8.69 \%)$. Malignant pathologies were observed in $36.95 \%$ patients. Most common malignant pathology seen was Cholangiocarcinoma (17.39\%) followed by periampullary carcinoma $(8.69 \%)$, carcinoma head of pancreas $(4.34 \%)$ and carcinoma gallbladder $(4.34 \%)$. Cholangiocarcinoma and periampullary carcinoma were more predominant in males. Least commonly observed malignant pathology was one case of metastatic lymph nodes $(2.17 \%)$ which was found in female patient.

Table 1 Age Distribution of Patients Studied

\begin{tabular}{|l|c|c|}
\hline $\begin{array}{l}\text { Age in } \\
\text { Years }\end{array}$ & $\begin{array}{c}\text { Number of } \\
\text { Patients }\end{array}$ & Percentage \\
\hline$<15$ & 4 & 8.68 \\
\hline $16-25$ & 5 & 10.86 \\
\hline $26-35$ & 4 & 8.68 \\
\hline $36-45$ & 2 & 4.34 \\
\hline $46-55$ & 7 & 15.21 \\
\hline $56-65$ & 11 & 23.91 \\
\hline $66-75$ & 12 & 26.08 \\
\hline $76-85$ & 1 & 2.17 \\
\hline Total & 46 & 100 \\
\hline
\end{tabular}

Table 2 Gender Distribution of Patients Studied

\begin{tabular}{|l|c|c|}
\hline Gender & Number of patients & Percentage \\
\hline Male & 22 & 47.82 \\
\hline Female & 24 & 52.17 \\
\hline Total & 46 & 100 \\
\hline
\end{tabular}

Table 3 Clinical Symptom Wise Distribution of Patients at Presentation

\begin{tabular}{|l|c|c|}
\hline \multicolumn{1}{|c|}{ Clinical Symptoms } & No. Of Patients & Percentage \\
\hline Jaundice & 41 & 89.13 \\
\hline Pain in abdomen & 21 & 45.65 \\
\hline Vomiting & 11 & 23.91 \\
\hline Loss of appetite & 9 & 19.56 \\
\hline Fever & 7 & 15.21 \\
\hline Distension of abdomen & 5 & 10.86 \\
\hline Loss of weight & 4 & 8.69 \\
\hline
\end{tabular}


Table 4 Benign Versus Malignant Causes of Biliary Obstruction in the Studied Population

\begin{tabular}{|l|c|c|}
\hline Type of Lesion & No. of Cases & Percentage \\
\hline Benign & 29 & 63.04 \\
\hline Malignant & 17 & 36.95 \\
\hline Total & 46 & 100 \\
\hline
\end{tabular}

Graph 1 Various Causes of Biliary Obstruction in the Studied Population

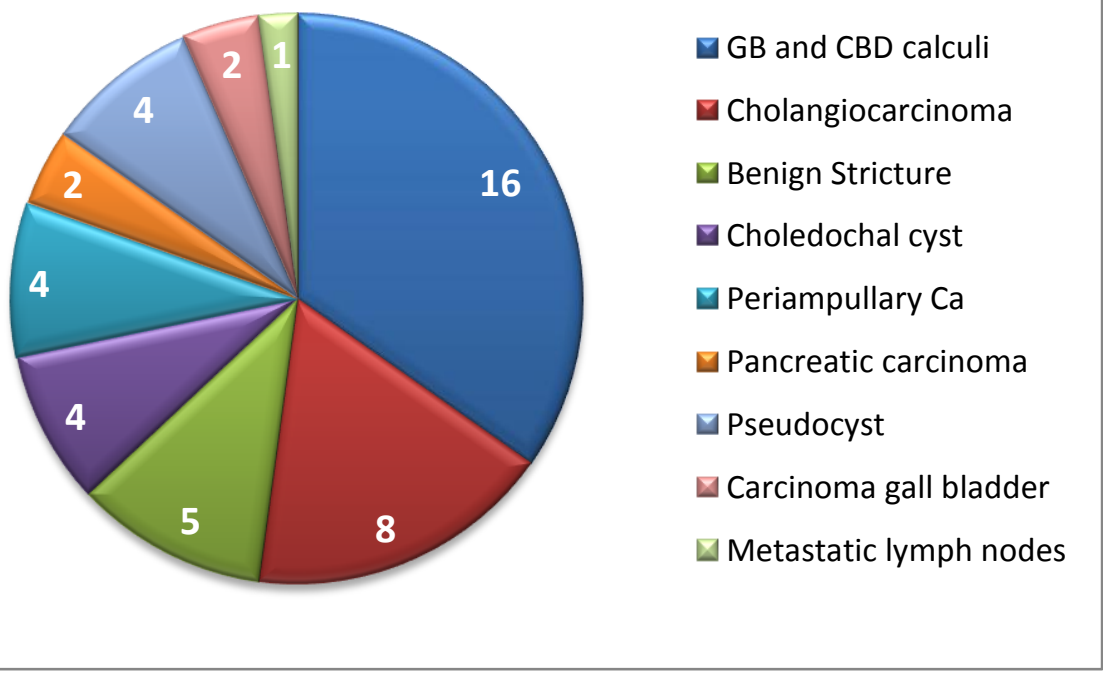

Table 5 Benign Causes of Biliary Obstruction in the Studied Population

\begin{tabular}{|l|c|c|c|c|c|c|}
\hline PATHOLOGY & USG (25) & \% & MRCP (30) & \% & SURGERY (29) & \% \\
\hline GB and CBD calculi & 15 & 51.72 & 17 & 58.62 & 16 & 55.17 \\
\hline Benign Stricutre & 3 & 10.34 & 5 & 17.24 & 5 & 17.24 \\
\hline Choledochal cyst & 4 & 13.79 & 4 & 13.79 & 4 & 13.79 \\
\hline Pseudo cyst & 3 & 10.34 & 4 & 13.79 & 4 & 13.79 \\
\hline
\end{tabular}

Table 6 Malignant Causes of Biliary Obstruction in the Studied Population

\begin{tabular}{|l|c|c|c|c|c|c|}
\hline Pathology & USG (13) & \% & MRCP (16) & \% & Surgery (17) & \% \\
\hline Cholangiocarcinoma & 7 & 41.17 & 8 & 47.05 & 8 & 47.05 \\
\hline Periampullary Carcinoma & 1 & 5.88 & 3 & 17.64 & 4 & 23.52 \\
\hline Carcinoma head of pancreas & 2 & 11.76 & 2 & 11.76 & 2 & 11.76 \\
\hline Carcinoma gall bladder & 2 & 11.76 & 2 & 11.76 & 2 & 11.76 \\
\hline Metastatic lymph nodes & 1 & 5.88 & 1 & 5.88 & 1 & 5.88 \\
\hline
\end{tabular}

Table 7 Comparison of Diagnostic Values of USG and MRCP in Benign Causes of Biliary Obstruction

\begin{tabular}{|l|c|c|c|}
\hline Modality & Sensitivity (\%) & Specificity (\%) & Accuracy (\%) \\
\hline USG & 84 & 100 & 86 \\
\hline MRCP & 96.55 & 100 & 96.66 \\
\hline
\end{tabular}

Table 8 Comparison of Diagnostic Value of USG and MRCP in Malignant Causes of Biliary Obstruction

\begin{tabular}{|l|c|c|c|}
\hline Modality & Sensitivity (\%) & Specificity (\%) & Diagnostic accuracy (\%) \\
\hline USG & 84.61 & 100 & 88.23 \\
\hline MRCP & 93.75 & 100 & 94.11 \\
\hline
\end{tabular}




\section{JMSCR Vol||07||Issue||01||Page 1120-1128||January}

Fig 1 Choledocholithiasis

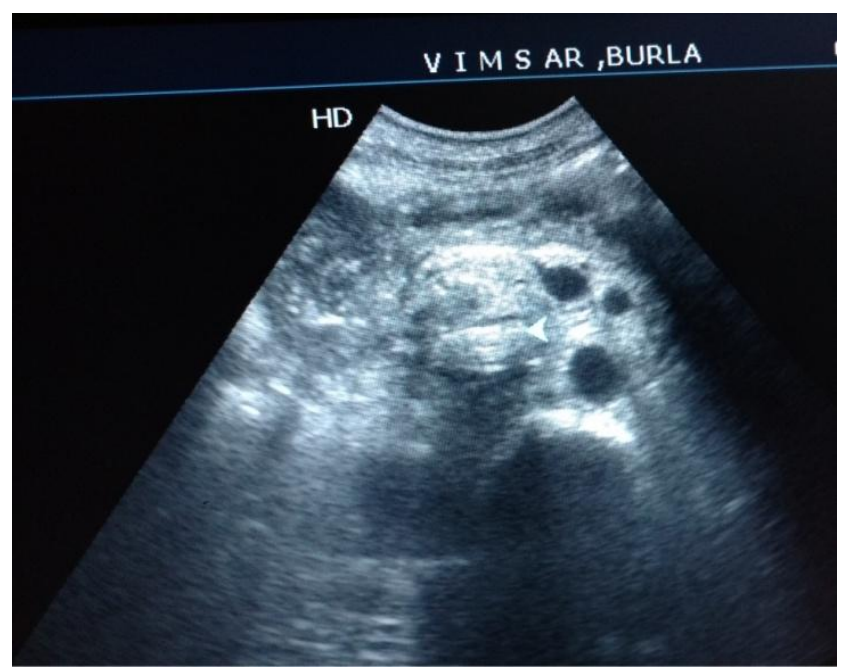

Figure (1A) USG showing echogenic calculus with PAS in distal CBD

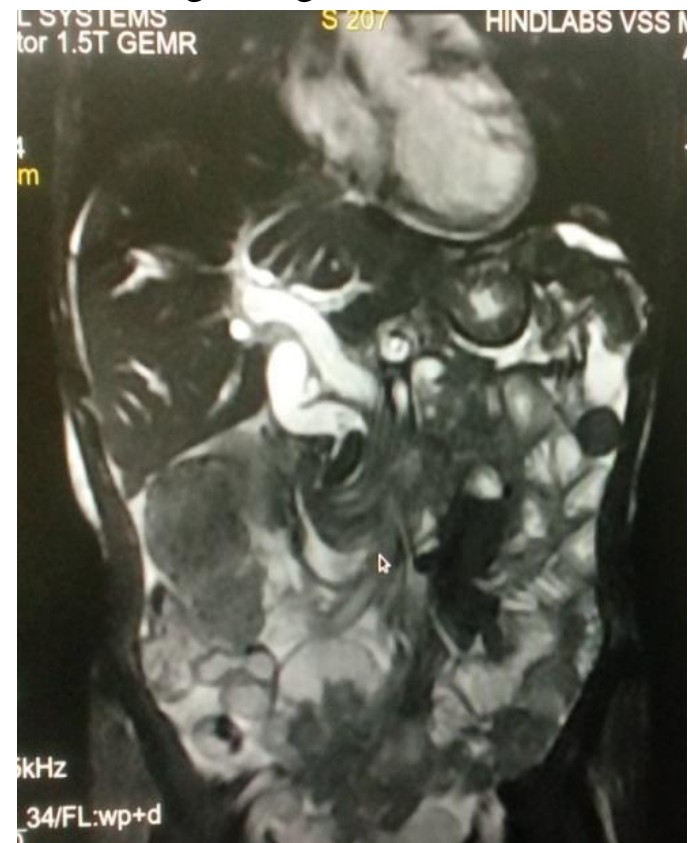

Figure (1B) MRCP image showing T2 hypointense filling defect in distal CBD

Fig 2 Cholangiocarcinoma

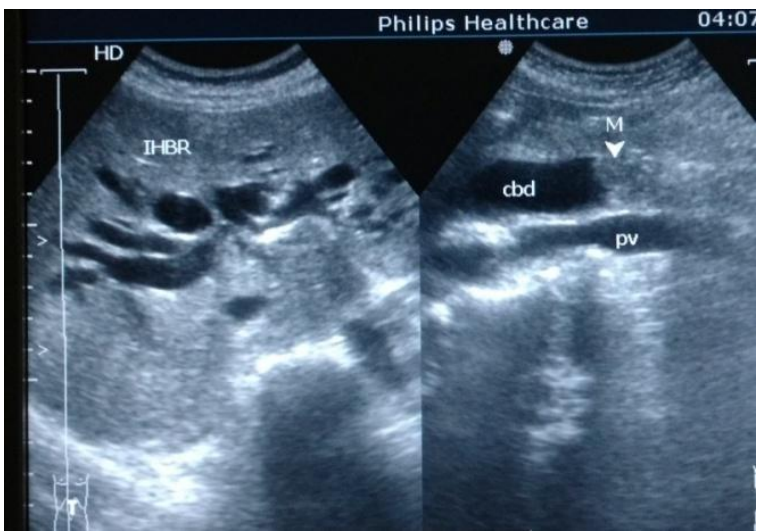

Figure (2A) USG showing echogenic lesion in distal CBD with dilatation of bile ducts proximal to it. 


\section{JMSCR Vol||07||Issue||01||Page 1120-1128||January}
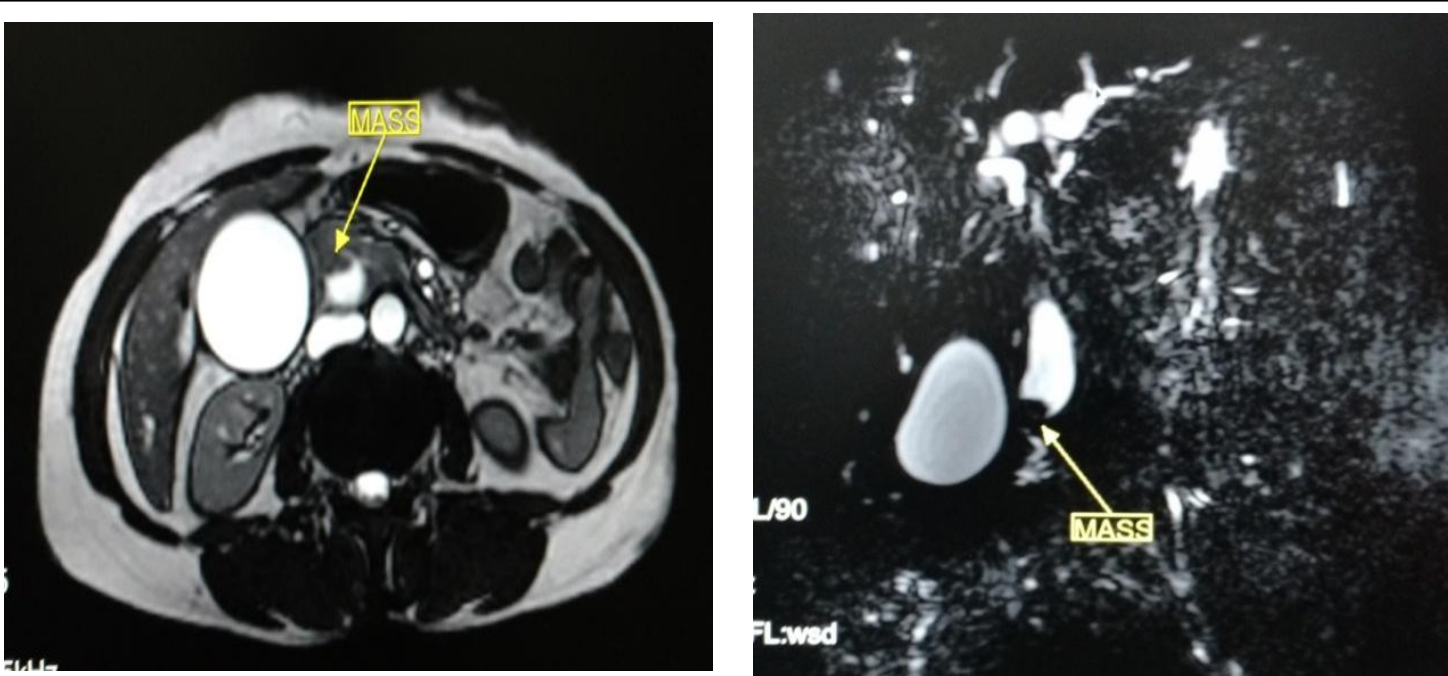

Fig 2 (2B \& 2C) MRCP showing illdefined heterogenous intensity lesion in the region of distal CBD. Moderate dilatation of proximal CBD and IHBR noted.

Fig 3 Periampullary Carcinoma

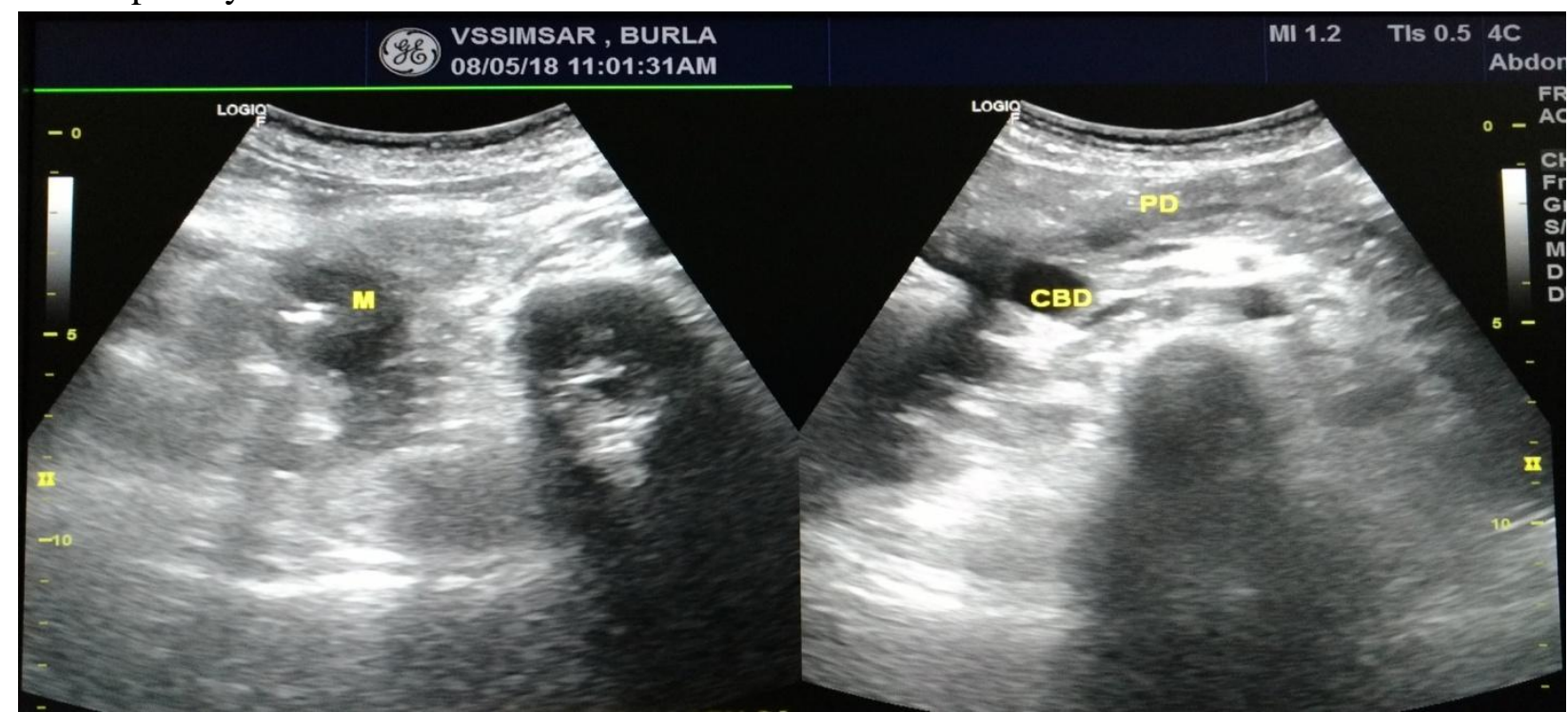

Fig 3 (3A \& 3B)USG showing hypoechoic lesion in periampullary region with dilatation of CBD \& PD.
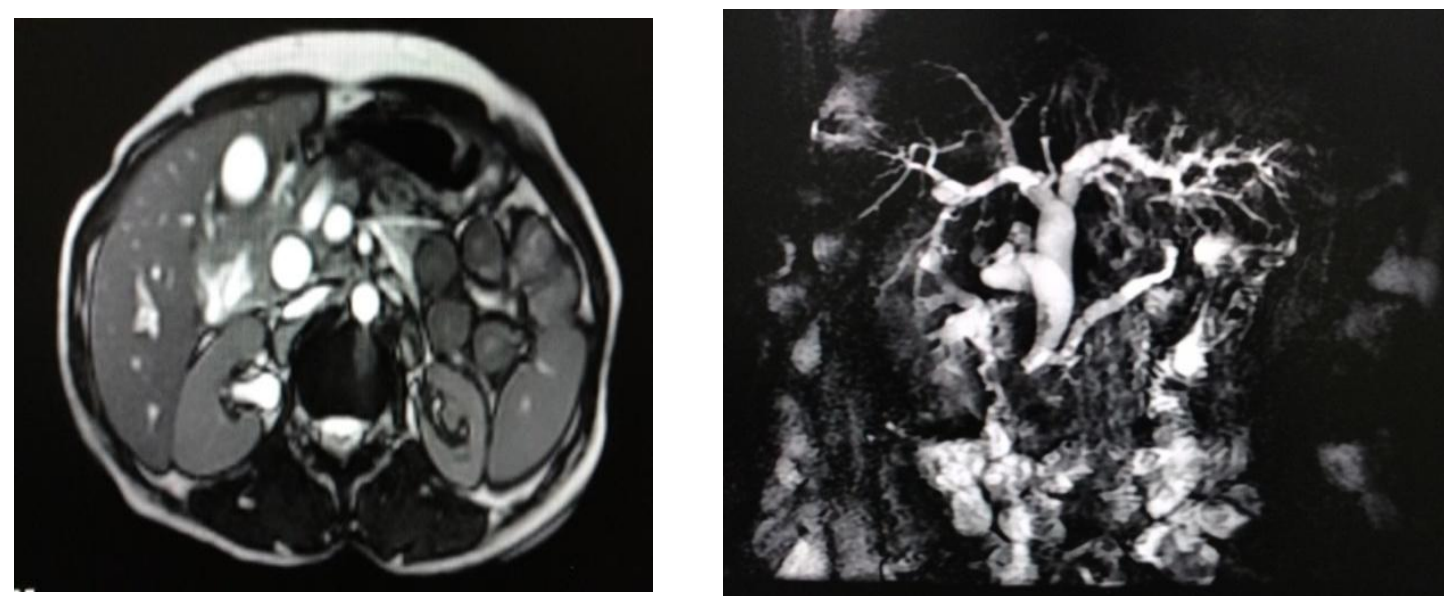

Fig 3 (3C \& 3D) MRCP showing illdefined T2 hypointense lesion at ampullary region with eccentric duodenal wall thickening. Dilated CBD with sudden cut off at periampullary region. PD is also dilated (double duct sign positive). 
Fig 4 Carcinoma Gallbladder

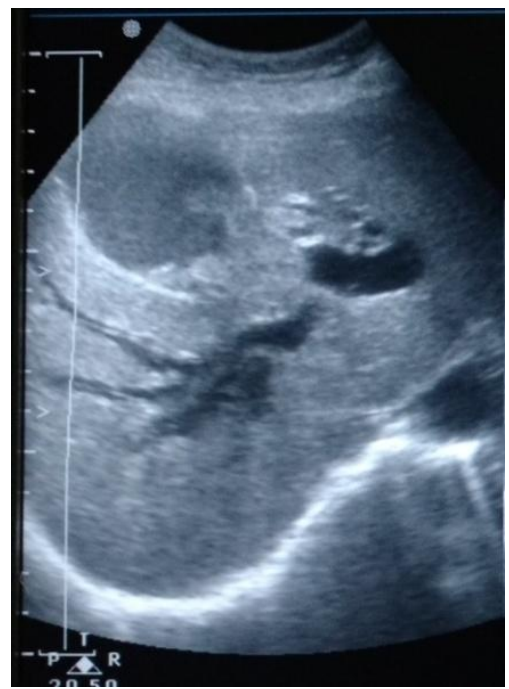

Fig 3 (4A) USG showing obstructive billiopathy secondary to invasion of CHD by GB neck mass
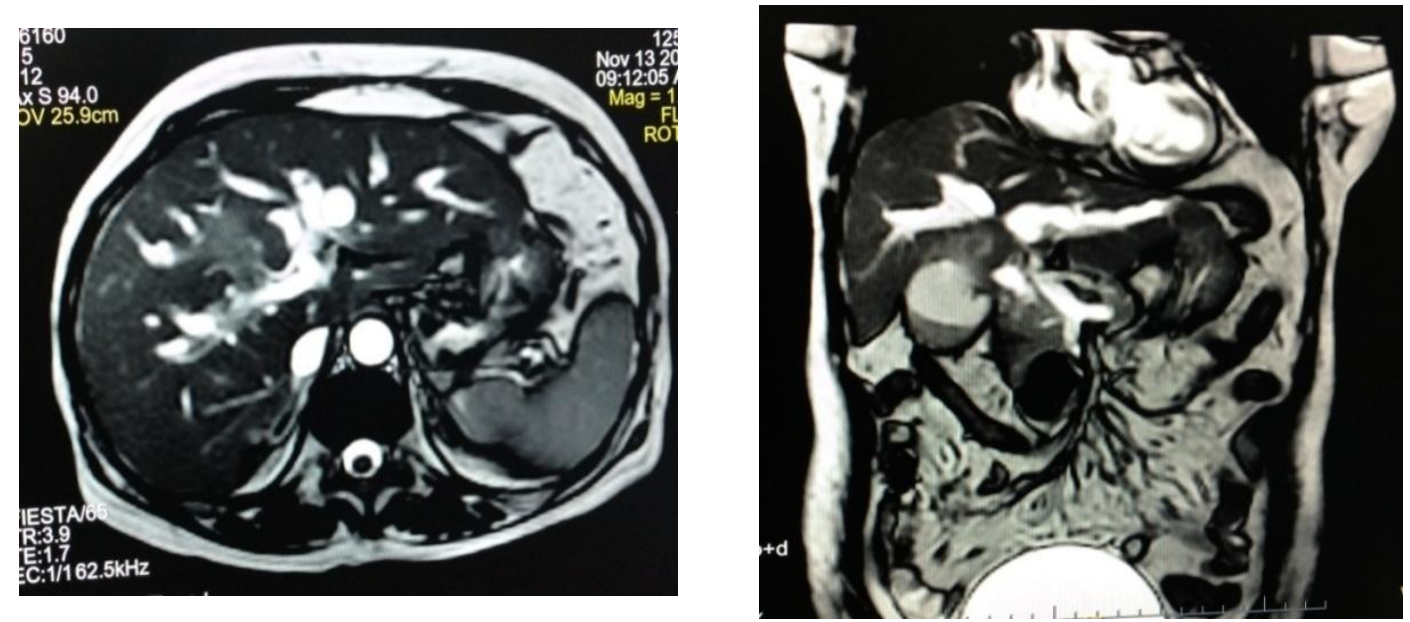

Fig 4 (4B \& 4C) MRCP showing iso to hypointense lesion in the region of neck of gallbladder, infiltrating into the CHD and thereby causing proximal dilatation of IHBR.

\section{Discussion}

From table no $1 \& 2-$ Out of 46 patients evaluated, $22(47.82 \%)$ patients were male and $24(52.17 \%)$ patients were female. The mean age of study population was 45.5 (range 4-82 years). The average age of patients with benign lesions was in the fourth decade while that of malignant lesion was in the sixth decade.

Upadhyaya et $\mathrm{al}^{6}$ studied 100 patients out of which $46 \%$ were male and $54 \%$ were female, Ferrari et $\mathrm{al}^{7}$ studies 131 patients; distribution of male patients in Ferrari et al was $47 \%$ while that of female $53 \%$. Soto et $\mathrm{al}^{8}$ studies 43 patients out of which male and $53 \%$ female. In our study of 46 patients, $48 \%$ were male and $52 \%$ were female patients. Percentage distribution of male to female is almost equal on our study. From above table sex distribution in our study closely matches with Upadhaya et al, Ferrari et al and Soto et al.

From table no 3- Regarding clinical symptoms most common clinical presentation in our study was jaundice seen in 41 (89\%) patients followed by pain abdomen seen in 21 (45.65\%) patients, while least common presentation was loss of weight seen in $4(8.7 \%)$ patients. Almost all patients presented with combination of symptoms. Schwartz et $\mathrm{al}^{9}$ in his study reported that most common presentation was jaundice seen in $68 \%$ patients followed by pain in abdomen seen in $25 \%$ patients which is similar with our study.

From table no 4- USG was done prior to MRCP for all patients. 29(63\%) benign and 17(37\%) 
malignant causes of biliary obstruction were detected in the study population. Most common pathology detected in our study is a benign entity, choledocholithiasis, constituting 16 cases of our study population followed by 8 cases of cholangiocarcinoma, a malignant pathology.

From table no 5- Sixteen cases of choledocholithiasis were detected in our study population. While USG diagnosed 15 lesions with cholelithiasis, it had difficulty in diagnosing distal CBD calculi which was easily picked up by MRCP. Our study is in concordance with Guibaud et $\mathrm{al}^{10} 1995$; in their study they found an accuracy of $100 \%$ in detecting CBD calculi on MRCP in cases with equivocal sonographic results. MRCP clearly shows the IHBR dilatation, caliber of CBD and the site of the calculus, especially in the distal CBD which is difficult to visualize on ultrasound. Of the 16 patients diagnosed with CBD and GB calculi, MRCP had accurately diagnosed all the 16 cases. Our study is in concordance with Soto et al ${ }^{8}$ 2000; In their study they found, sensitivity of $94 \%$ and specificity of $100 \%$ for detecting biliary calculi on MRCP. Varghese et al ${ }^{11}$ who reported $91 \%$ sensitivity, specificity of $98 \%$ and diagnostic accuracy of $97 \%$ on MRCP. Sugiyama et $\mathrm{al}^{12}$ reported $91 \%$ sensitivity, specifity of $100 \%$ and diagnostic accuracy of $97 \%$ on MRCP. ${ }^{71}$

Four cases of anatomic variants, choledochal cysts were present in our study. All 4 cases were diagnosed correctly by MRCP. Our study is in concordance with Bhatt et $\mathrm{al}^{13}$ in their study they found $100 \%$ accuracy for MRCP in diagnosing anatomical variants.

In four cases of choledochal cyst seen in our study, MRCP yielded diagnostic information by providing exact anatomical map for presurgical evaluation. Bhatt et $\mathrm{al}^{13}$ reported choledochal cyst in $10 \%$ of cases in his study. Our findings are consistent with Bhatt et al.

Four cases $(28.69 \%)$ of pseudocyst resulting in biliary obstruction were present in our study which was correctly diagnosed by MRCP.
From Table 6- In our study of 46 cases, cholangiocarcinoma was seen in $8(17.39 \%)$ cases and Periampullary carcinoma $4(8.69 \%)$ cases.

Schwartz et $\mathrm{al}^{9}$ in his study of 32 cases reported cholangiocarcinoma in $21.8 \%$ cases, Ca pancreas inn $37.5 \%$ cases and Periampillary $\mathrm{Ca}$ in $6.2 \%$ cases. Soto et $\mathrm{al}^{8}$ in his study of 43 cases reported cholangiocarcinoma in $13.9 \%$ cases, Ca pancreas in $18.6 \%$ cases and Priampullary $\mathrm{Ca}$ in $9.3 \%$ cases.

Percentage distribution of cholangiocarcinoma in our study matches with Schwartz et al. Percentage distribution of periampullary Carcinoma in our study matches with Soto et al. Overall Percentage distribution of malignant pathologies in our study closely matches with Soto et al.

Among the 2 cases of carcinoma head of the pancreas, MRCP accurately diagnose all 2 cases of carcinoma head of the pancreas. Two cases of carcinoma gall bladder and another case of Metastatic lymph nodes causing biliary obstruction were diagnosed by both the modalities achieving $100 \%$ accuracy.

In our study final diagnostic criteria is histopathology and postoperative findings. In our study of 46 cases, surgery/Histopathological correlation was done in 41 cases. Out of 46 cases, 4 cases were inoperable tumours. In these cases diagnosis was confirmed by FNAC. However in 1 case of Caroil's disease surgery/Histopath/FNAC was not advisable hence, MRCP diagnosis was considered as final diagnostic.

Depending upon these 45 case in which surgery/histopathological/FNAC correlation was done, following statistical values are derived.

From Table no 7 - Sensitivity, specificity and diagnostic accuracy for benign pathologies in our study was $84 \%, 100 \%$ \& $86 \%$ respectively on ultrasound. On MRCP sensitivity was $96.55 \%$, specificity was $100 \%$ and accuracy was $96.66 \%$ for cases with benign conditions.

Verma et $\mathrm{al}^{14}$ demonstrated the sensitivity and specificity of $85.3 \%$ and $88.4 \%$ on ultrasound, $92.3 \%$ and $86 \%$ on MRCP respectively for detecting the benign etiology of obstruction. 
Ferrari FS et $\mathrm{al}^{7}$ demonstrated similar findings for benign lesions in their study. The diagnostic accuracy, sensitivity and specificity of USG was $78.62 \%, 16.67 \%, 97.29 \%$ and MRCP was $93.13 \%, 90 \%, 94 \%$ respectively.

From Table no 8- Sensitivity and specificity for malignant pathologies in our study was $84.61 \%$ and $100 \%$ respectively on USG while that on MRCP was $93.75 \%$ and $100 \%$ respectively. Likelihood ratio can't be calculated as specificity is $100 \%$ From this it is clear that MRCP is more sensitive in detecting pancreato-biliary malignancies than USG, while specificity of both USG and MRCP remains same.

Verma et $\mathrm{al}^{14}$ demonstrated the sensitivity and specificity of $88.4 \%$ and $85.3 \%$ on ultrasound, $86 \%$ and $92 \%$ on MRCP respectively for detecting the malignant etiology of obstruction . Ferrari FS et $\mathrm{al}^{7}$ demonstrated the diagnostic accuracy, sensitivity and specificity of USG $93.13 \%$, $61.12 \%, 98.23 \%$ and $93.13 \%, 90 \%, 94 \%$ of MRCP respectively.

\section{Conclusion}

MRCP was superior to Ultrasound. Ultrasound still remains the primary investigative modality of choice. MRCP serves as an accurate and non invasive, non ionizing imaging method for evaluation of pancreatico-biliary anatomy and pathology. It is very useful tool in case of obese patients. MRCP is the modality of choice for optimal characterization of the causative lesions in most of the cases obstructive jaundice which allows safe surgical management decisions. Potentially useful in patients undergoing biliary enteric anastomosis for knowing the level and extent of strictures.

\section{References}

1. Hakansson K, Ekberg O, Hakansson HO, Leander P: MR and ultrasound in screening of patients with suspected biliary tract disease. Acta Radiol. 2002; 43:80-86.

2. Fleischmann D, Ringl H, Schofl R, Potzi $\mathrm{R}$, Kontrus M, Henk C, et al. Three dimensional spiral CT cholangiography in patients with suspected obstructive biliary disease: comparison with endoscopic retrograde cholangiopancreatography. Radiology. 1996; 198: 861-8.

3. Gibson RN, Yeung E, Thompson LN, Carr DH, Benjamin IS, Blumgart LH, Allison DJ. Bile duct obstruction: Radiologic evaluation of level, cause, and tumour resectability. Radiology. 1986;160:43-7.

4. Zandrino F, Benzi L, Ferretti ML, et al. Multislice CT cholangiography without biliary contrast agent: technique and initial clinical re- sults in the assessment of patients with biliary obstruction. Eur Radiol. 2002; 12: 1155-61.

5. Reinhold C, Bret PM. MR cholangiopancreatography. Abdom Imaging. 1996; 21: 105-16.

6. Upadhayay V, Upadhyaya DN, Unsari MA, Shukla VK. Comparative assessment of imaging modalities in biliary obstruction. Indian $\mathrm{J}$ Radiol Imaging 2006;16:577-82.

7. Ferrari FS, Fantozzi F, Tasciotti L, Vigni F, Scotto F, Frasci P. US, MRCP, CCT and ERCP: A comparative study in 131 patients with suspected biliary obstruction. Med Sci Monit 2005;11:MT8-18.

8. Soto JA, Alvarez O, Múnera F, Velez SM, Valencia J, Ramírez N. Diagnosing bile duct stones: Comparison of unenhanced helical CT, oral contrast-enhanced CT cholangiography, and MR cholangiography. AJR Am J Roentgenol 2000;175:1127-34.

9. Schwartz LH, Black J, Fong Y et al. gallbladder carcinoma Findings at MR imaging with MR cholangiopancreatography. J Comput Assist Tomogr 2002;26:405-410.

10. Guibaud L, Bret PM, Reinhold C et al (1994) Diagnosis of choledocholithiasis: value of MR cholangiography. AJR Am J Roentgenol 163:847-850 
11. Verghese J.C, Liddell R.P, Rarrell et al. The diagnostic accuracy of magnetic resonance cholngiopancreatography and ultrasound compared with direct cholangiography in the detection of choledocholithiasis. Clinical Radiology. 1999;54(9):604-614.

12. Sugiyama M, Atomi Y \& Hachiya J et al. Magnetic resonance cholangiography using half-Fourier acquisition for diagnosing choledelocholithiasis. American Journal of Gastronterology.1998; 93 (10):1886-1890.

13. Bhatt C, Shah PS, Prajapati HJ, Modi J et al. Comparison of Diagnostic Accuracy between USG and MRCP in Biliary and Pancreatic Pathology. Ind J Radiol Imag. 2005; 15:177-181.

14. Verma SR, Sahai SB, Gupta PK. Munshi A, Verma SC, Goyal P, obstructive Jundice- Aetiological Spectrum, clinical biochemical and Radiological Evaluation At A Teriary Care Teaching Hospital. The Internet Journal of Tropical Medicine 2010 Volume 7 Number 2. 